EVTDDfallis.pdf

$11 / 10 / 07$

\title{
EPISTEMIC VALUE THEORY AND THE DIGITAL DIVIDE
}

\author{
Don Fallis \\ School of Information Resources \\ University of Arizona \\ fallis@email.arizona.edu \\ Originally published in \\ Information Technology and Social Justice \\ eds. Emma Rooksby and John Weckert, Idea Group, (2007): 29-46 \\ Reprinted in \\ Global Information Technologies: Concepts, Methodologies, Tools, and Applications \\ ed. Felix B. Tan, Information Science Reference (2008): 3091-3104
}




\title{
EPISTEMIC VALUE THEORY AND THE DIGITAL DIVIDE
}

\begin{abstract}
The digital divide refers to inequalities in access to information technology. Those people who do not have access to information technology are at a significant economic and social disadvantage. As with any other policy decision, in order to evaluate policies for dealing with the digital divide, we need to know exactly what our goal should be. Since the principal value of access to information technology is that it leads to knowledge, work in epistemology can help us to clarify our goal in the context of the digital divide. In this paper, I argue that epistemic value theory can help us to determine which distribution of knowledge to aim for. Epistemic value theory cannot specify a particular distribution to aim for, but it can significantly narrow down the range of possibilities. Additionally, I indicate how the exercise of applying epistemic value theory to the case of the digital divide furthers work in epistemology.
\end{abstract}

\section{Keywords}

Digital Divide, Epistemology, Equality of Access, Information Ethics, Knowledge Acquisition, Value of Information

\section{INTRODUCTION}

The digital divide refers to inequalities in access to information technology, such as personal computers, cellphones, PDAs, and the Internet. ${ }^{1}$ Some people, the so-called information have-nots, have significantly less access than other people, the so-called 
information haves. This lack of access puts the information have-nots at a significant economic and social disadvantage (cf. Hacker and Mason 2003, p. 101). As a result, there is a large literature on what should be done about the digital divide (see, e.g., Doctor 1992, Chabrán 2001, Compaine 2001, Mueller 2001, De George 2003, pp. 254260, Hacker and Mason 2003). ${ }^{2}$

Most of this literature focuses on what the consequences are likely to be of adopting various policies for dealing with the digital divide. For example, some authors (e.g., Compaine 2001, Mueller 2001) contend that the operation of the free market will eliminate the digital divide. Other authors (e.g., Chabrán 2001, De George 2003) contend that eliminating the digital divide will require some intervention into the operation of the free market. ${ }^{3}$ However, there is very little discussion of what consequences we would like to bring about (cf. Hacker and Mason 2003). ${ }^{4}$

As with any other policy decision, we need to know which consequences count as good consequences in order to evaluate potential digital divide policies (cf. Kirkwood 1997, p. 11). In other words, we need to know exactly what our goal should be. For example, should the goal be to reduce inequalities in access to information technology or should the goal be to provide the information have-nots with more access? Clarifying our goal requires an analysis of the value of access to information technology.

In this paper, I argue that the principal value of access to information technology is that it leads to knowledge. As a result, work in epistemology can help us to clarify our goal in 
the context of the digital divide. In particular, I show how epistemic value theory can help us to determine which distribution of knowledge to aim for. ${ }^{6}$ Epistemic value theory cannot specify a particular distribution to aim for, but it can significantly narrow down the range of possibilities. Finally, I indicate how the exercise of applying epistemic value theory to the case of the digital divide can help us to develop epistemic value theory itself.

\section{THE VALUE OF ACCESS TO INFORMATION TECHNOLOGY}

Some people have suggested that the digital divide is not a very important issue. For example, the former chairman of the Federal Communication Commission, Michael Powell, famously compared unequal access to information technology with unequal access to luxury automobiles. ${ }^{7}$ There is, however, an important difference between the two.

Unlike access to luxury automobiles, access to information technology is a necessity of modern life. It is becoming very difficult for an individual without access to information technology to get all of the information that she needs to conduct her daily life. The Internet, in particular, is becoming a primary source of information about job opportunities, health care, travel, government services, paying taxes, political candidates, etc. Admittedly, most of this information is still available from other sources (e.g., books and newspapers). However, since it is quickly becoming prohibitively expensive and/or time-consuming to get this information from other sources, people without access to information technology are effectively denied access to this information. As a result, it 
has even been suggested that access to information technology is now a basic human right (cf. United Nations 1948, Johnson 1991, pp. 212-214, Chabrán 2001, p. 138).

As Jeremy Moss (2002) points out, access to information technology opens up wider possibilities for action. For example, an individual can pay his or her taxes online, make travel arrangements, buy and sell products, etc. The principal value of access to information technology, however, is that it leads to knowledge (cf. Tichenor et al. 1970, Lievrouw and Farb 2003, p. 504). ${ }^{8}$ Much of what we know about the world comes through our access to information technology, such as the Internet (cf. Fallis 2006a). In addition, access to information technology has many of the benefits that it does precisely because it allows people to acquire knowledge. ${ }^{9}$ Knowledge of what jobs are available, for example, helps one to take advantage of economic opportunities. ${ }^{10}$ Also, knowledge of the positions of political candidates helps one to participate effectively in the public sphere. As a result, when evaluating digital divide policies, it is useful to focus on knowledge rather than on the diverse benefits of having such knowledge (cf. Fallis 2004b, pp. 102-103). ${ }^{11}$

\section{EPISTEMIC VALUE THEORY}

This analysis of the value of access to information technology, however, does not tell us enough to actually evaluate digital divide policies. Several different digital divide policies may all increase the amount of knowledge in society. But they will undoubtedly distribute this knowledge in different ways. Thus, in order to evaluate digital divide policies, we also have to be able to say which distribution of knowledge is best. ${ }^{12}$ 
The question of how to distribute knowledge is a question of distributive justice.

However, since we are concerned specifically with how knowledge should be distributed, this is arguably also a question for epistemology. Epistemic goodness is an important part of overall goodness in the context of the digital divide. And, according to Alvin Goldman (1999), the job of social epistemology is to identify social policies (such as digital divide policies) that have good epistemic consequences.

Everybody having all knowledge is clearly the epistemically ideal distribution of knowledge. Epistemologists often discuss such ideal epistemic goals in the case of individuals. For example, Roderick Chisholm (1977) claims that a person should try "his best to bring it about that, for every proposition $h$ that he considers, he accepts $h$ if and only if $h$ is true" (p. 14). However, given the limits on our time and resources, it is just not possible for a person to have all and only true beliefs. Similarly, it is just not possible for everybody to have all knowledge. As a result, being able to say that everybody having all knowledge is the epistemically ideal distribution does not really help us to evaluate digital divide policies.

In order to evaluate digital divide policies, we need a more fine-grained epistemic value theory (cf. Goldman 1999, p. 87, Fallis 2004b). ${ }^{13}$ In other words, we need to be able to say whether one distribution of knowledge is epistemically better than another. In particular, we need to be able to say which of the distributions of knowledge that we can actually bring about is epistemically best. 
Several epistemologists (e.g., Levi 1967, Maher 1993) have developed epistemic value theories that can be applied to the epistemic states of individuals (usually, scientists). However, there are many situations, such as the evaluation of digital divide policies, where we need to know how knowledge should be distributed among many different people (cf. Goldman 1999, pp. 93-94). Goldman (1999) has recently developed an epistemic value theory that can also be applied to the epistemic states of groups. He has used this theory to evaluate policies in several different areas, such as the law, education, and science. But his theory is applicable to any area (including the digital divide) where epistemic consequences are at stake.

Fortunately, there are some clear-cut constraints on the epistemic betterness relation that are relevant to whether one distribution of knowledge is epistemically better than another ${ }^{14}$ For example, it is clearly epistemically better for a person to have more knowledge rather than less (cf. Goldman 1987, p. 128). ${ }^{15}$ In other words, it is epistemically better to have knowledge on a particular topic than to be ignorant (or in error) on the topic. In addition, it follows that it is epistemically better for more people to have knowledge rather than fewer (cf. Goldman 1987, pp. 128-129).

These are the two most obvious constraints on the epistemic betterness relation. But it should be noted that there may very well be additional constraints that are relevant in the context of the digital divide. For example, the first constraint above essentially says that it is epistemically better for there to be more knowledge tokens (my true belief that $p$, 
your true belief that $p$, etc.) rather than fewer. However, it is also clearly epistemically better for there to be more knowledge types (my true belief that $p$, your true belief that $q$, etc.) rather than fewer (cf. Fallis 2004b, p. 109). This additional constraint is also relevant to whether one distribution of knowledge is epistemically better than another. In this paper, however, I will set this complication aside.

Let us say that a distribution of knowledge $D$ is epistemically permissible if no other distribution that we can actually bring about is epistemically better than $D$. Epistemic value theory clearly recommends that we always aim for an epistemically permissible distribution. In addition, let us say that a distribution of knowledge $D$ is epistemically required if $D$ is epistemically better than any other distributions that we can actually bring about. Epistemic value theory recommends that we aim for the epistemically required distribution if there is one.

\section{A "Utilitarian" Distribution of Knowledge}

It would be nice if there were a distribution of knowledge that was epistemically required. Goldman $(1999$, p. 93) seems to take the position that there is such a distribution. In particular, he suggests that a "utilitarian" distribution of knowledge that maximizes that average amount of knowledge possession in society is epistemically better than any alternative (cf. Goldman 2002, p. 216, Fallis 2004b, pp. 107-108). ${ }^{16}$ But while this distribution may be epistemically permissible, it does not seem to be epistemically required. ${ }^{17}$ 
In fact, Goldman himself actually gives an example of an epistemically permissible distribution that does not maximize knowledge possession. When discussing how a ship's captain wants knowledge to be distributed among her crew, Goldman (1999) notes that "information must be distributed to the people with a "need to know" ... even if that does not translate into a high average knowledge across the whole team" (p. 96). Even though she does not want to maximize the average amount of knowledge possessed by her crew, the captain still aims for knowledge rather than ignorance or error (i.e., her preferences obey the two constraints on epistemic betterness given above).

Furthermore, even though a "utilitarian" distribution may be epistemically permissible, it is probably not the distribution that we want to aim for in the context of the digital divide. The utilitarian distribution is consistent with a very wide digital divide and with the information have-nots actually being worse off. Maximizing the average amount of knowledge possession in society might require that some people (such as the information have-nots) know very little. ${ }^{18}$

\section{An "Egalitarian" Distribution of Knowledge}

Given the potential problems with aiming for a "utilitarian" distribution of knowledge, it might be suggested that we should try to distribute knowledge equally among the members of society. Such an "egalitarian" distribution would completely eliminate the digital divide. However, according to a strict egalitarian, "it is better, for the sake of equality, to take good from better-off people without giving any to the less well-off" (Broome 1991, p. 184). Thus, in an "egalitarian" distribution, some people might have to 
have less knowledge than they could have had. In other words, an "egalitarian" distribution is not epistemically permissible.

Furthermore, it is also probably not the distribution that we want to aim for in the context of the digital divide. There are many cases where everybody does better if goods are not equally distributed. For example, train service can be provided to more people when there are several different levels of service (some of which some people may not be able to afford) rather than just one level (cf. Ekelund 1970, pp. 275-276). ${ }^{19}$ This suggests that we ought to be more concerned that knowledge be distributed equitably (or fairly) than that it be distributed equally (cf. Lievrouw and Farb 2003, pp. 502-504).

\section{A "Rawlsian" Distribution of Knowledge}

Fortunately, there are epistemically permissible distributions of knowledge that seem to distribute knowledge equitably. One such distribution is suggested by the work of John Rawls (1971) on distributive justice. According to Rawls (1971), "the social order is not to establish and secure the more attractive prospects of those better off unless doing so is to the advantage of those less fortunate" (p. 75). In other words, inequalities in the distribution of primary goods (such as knowledge) can be acceptable, but only if such inequalities are to the advantage of the least well off (such as the information havenots). ${ }^{20}$ Thus, we might want to aim for a "Rawlsian" distribution that maximizes the amount of knowledge possessed by the information have-nots. ${ }^{21}$ 
Such a distribution does not insure an equal distribution of knowledge. For example, we probably need to have many highly knowledgeable experts in information technology in order to facilitate knowledge acquisition among the information have-nots. However, such a distribution does insure that the information have-nots have as much knowledge as possible. In addition, taking this distribution as the goal of digital divide policy is in line with the view that access to information technology is a right that everyone has (cf. United Nations 1948, Johnson 1991, pp. 212-214, Lievrouw and Farb 2003, p. 512). ${ }^{22}$

\section{THE BAD CONSEQUENCES OF KNOWLEDGE}

The case of the "egalitarian" distribution establishes that not all distributions of knowledge are epistemically permissible. But unless we can identify very tight constraints on the epistemic betterness relation, there are still going to be numerous epistemically permissible distributions of knowledge. The "Rawlsian" and "utilitarian" distributions are just two examples. And epistemology will not be able to tell us which of these epistemically permissible distributions we should aim for. Nevertheless, it seems clear that we should aim for the epistemically permissible distribution of knowledge that has the best consequences all things considered. ${ }^{23}$

As noted above, of the epistemically permissible distributions, Goldman favors a "utilitarian" distribution of knowledge. However, Goldman (2002, pp. 218-220) has recently suggested that we should not necessarily aim for an epistemically permissible distribution of knowledge at all. After all, if we want to aim for the distribution of knowledge that has the best consequences all things considered, why should we limit 
ourselves to looking among the epistemically permissible distributions? Since epistemic goodness is only part of overall goodness, it could be that the distribution with the best overall consequences is not epistemically permissible. That this might actually be the case is suggested by the fact that having knowledge can sometimes have bad consequences (cf. Fallis 2004b, p. 103).

Given this possibility, Goldman suggests that we should simply aim for the distribution of knowledge that has the best consequences all things considered. In other words, we should ignore the recommendations of epistemic value theory. The idea here is that epistemology should simply be concerned with what the epistemic consequences of various policies are likely to be. It need not take a position on which consequences count as good consequences, epistemically or otherwise.

However, Goldman's suggestion is not actually in conflict with the recommendations of epistemic value theory as long as the distribution of knowledge that has the best overall consequences is epistemically permissible. In the remainder of this section, I will address, in order of increasing relevance to the digital divide, the various ways in which having knowledge can have bad consequences. I will make the case that the good consequences are likely to outweigh the bad consequences. ${ }^{24}$ In other words, I will argue that the distribution with the best overall consequences is likely to be epistemically permissible.

\section{Knowledge that Harms Others}


Having additional knowledge is sometimes harmful to other people (cf. Fallis 2004b, p. 103). For example, when terrorists acquire more knowledge about reservoirs and dams, they are better able to harm the rest of us (cf. Litchblau 2001). This, however, seems to be a rather unlikely scenario in the context of the digital divide. ${ }^{25}$ Only very specific pieces of knowledge (in the hands of very specific people) would be problematic.

Having additional knowledge is rarely harmful to other people. In fact, as Bruce Kingma (2001, p. 69) points out, people usually benefit from other people having knowledge. For example, we are better off if other people are better informed about traffic laws, disease prevention, and the democratic process as a result of access to information technology. Thus, it seems likely that the benefits of knowledge will outweigh these risks

\section{Knowledge that Harms the Knower}

In addition to sometimes being harmful to others, having additional knowledge is sometimes harmful to the people who have it (cf. Nozick 1993, pp. 69-70). The knower is certainly epistemically better off, but she might be worse off all things considered. For example, a person who is trying to quit smoking is better off not knowing where her roommate keeps his cigarettes. ${ }^{26}$ This worry about harm coming to the knower has actually been raised in the context of the digital divide. For example, Soraj Hongladarom (2002, pp. 4-7) describes how a culture can be destabilized by access to information that comes from other cultures (cf. De George 2003, p. 258). 
In fact, a culture can be destabilized by access to information that comes from that very culture. For example, Michael Brown (2003, p. 34) describes a case where ethnographic (in this case, religious) knowledge had been collected about an Aboriginal tribe in Australia. The tribe had reason to believe that the dissemination of this knowledge within their community would have bad consequences. ${ }^{27}$ In particular, they were worried that it would "undermine the social and religious stability of their hard-pressed community" if this knowledge got into the hands of "children, women, and uninitiated Aboriginal men.”

Even so, it is again only very specific pieces of knowledge that would be problematic. In general, having additional knowledge is beneficial to the knower. ${ }^{28}$ Knowledge allows people to figure out how to get what they want (cf. Goldman 1999, pp. 73-74). Knowledge about job opportunities and about political candidates are just two examples. In fact, there is evolutionary pressure for people to be successful at acquiring knowledge (cf. Papineau 2000). Our ancestors were only able to pass on their genes because they knew things like whether a predator was nearby and where food could be found.

This suggests that information policies that facilitate knowledge acquisition will typically have good consequences for the people who acquire the knowledge. Thus, in evaluating information policies, it makes sense for us to focus on practices that lead to epistemically permissible distributions. This is so despite the fact that such policies will, in rare circumstances, have some bad consequences. Consider an analogy. Public health policies that facilitate hygiene will typically have good consequences. Thus, it makes 
sense for public health officials to focus on hygienic practices even though there is a small chance that such practices will have some bad consequences. For example, it was actually better hygiene that led to the outbreak of polio at the beginning of the twentieth century (cf. Rogers 1992).

Finally, there is one particular way in which having additional knowledge can harm the knower that should be explicitly addressed. Namely, more knowledge can actually sometimes lead people to acquire false beliefs that can have bad consequences (cf. Nozick 1993, p. 69). ${ }^{29}$ For example, it is frequently better not to perform a diagnostic test even if that test accurately reports the presence of indicators of disease (cf. van den Hoven 1995, p. 10, Kolata 2001). On learning the results of such tests, patients often overestimate the likelihood of disease and undertake unnecessary (and sometimes harmful) courses of treatment. For similar reasons, evidence is sometimes excluded from a court of law even though it is accurate because the jury is likely to misestimate its probative value (cf. Goldman 1999, p. 294). With their limited experience with information technology, it seems legitimate to worry that the information have-nots might make such errors (e.g., be misled by inaccurate information on the Internet).

However, the appropriate solution (in the general case as well as in the specific context of the digital divide) is not to provide people with less knowledge, but to provide them with even more knowledge. For example, it is better to educate juries so that they will not be misled by evidence (cf. Goldman 1999, p. 295). Similarly, it is better to teach people how to evaluate the accuracy of information on the Internet rather than simply keeping 
them from accessing this information (cf. Fallis 2000, pp. 313-314).

\section{Inequalities in Knowledge Possession}

There is another way in which having additional knowledge can have bad consequences that is especially relevant in the context of the digital divide. It is possible to increase the amount of knowledge that everybody possesses and, at the same time, to increase the digital divide. In other words, it is possible that an epistemically permissible distribution will involve huge inequalities between the amount of knowledge possessed by the information haves and the amount of knowledge possessed by the information have-nots.

Here is an example of how this can happen: One way in which people have tried to reduce inequalities in access to information technology is by providing free Internet access at public libraries. This policy certainly has the benefit of increasing the amount of knowledge that information have-nots are able to acquire. However, it turns out that the people that make the most use of such access tend to be those that already have Internet access at home (cf. Hull 2003, p. 135). Thus, providing such access would actually seem to increase, rather than reduce, the knowledge gap between the information haves and the information have-nots. ${ }^{30}$

Such inequalities can harm the information have-nots, even if they have more knowledge than they would have had otherwise (cf. van den Hoven 1995, p. 16). For example, people often prefer to have a lesser amount of some good (e.g., income, beauty, knowledge) and do better relative to others than to have a greater amount of that good and do worse relative to others (see Solnick and Hemenway 1998). But it is not 
necessarily just a matter of preferences not being satisfied, huge inequalities in the distribution of knowledge might allow the information haves to impose their will on the information have-nots (cf. Moss 2002). ${ }^{31}$ For example, investment advisors, automobile repairmen, and totalitarian governments have all been known to take advantage of people's ignorance. Thus, the overall costs of distributing knowledge in a way that involves huge inequalities might very well exceed the epistemic benefits. ${ }^{32}$

However, the epistemically impermissible "egalitarian" distribution is not the only way to avoid such inequalities. It is also clearly possible to bring about epistemically permissible distributions that do not involve huge inequalities. We can increase knowledge possession and minimize inequalities by engaging in activities that are specifically designed to make the information have-nots better off. For example, instead of providing free Internet access equally in all public libraries, we might put more of our resources toward providing free Internet access in public libraries in poorer neighborhoods. In addition, we might put more of our resources toward giving information have-nots the online skills that will allow them to take advantage of this access.

Furthermore, epistemically permissible distributions that do not involve huge inequalities will arguably have very good consequences. ${ }^{33}$ As noted above, for example, we are typically better off if other people are well informed about all sorts of things. Thus, while many epistemically permissible distributions may involve huge inequalities and have bad consequences, there also seem to be many epistemically permissible distributions that do 
not. In other words, by focusing on epistemically permissible distributions, we are not limiting ourselves to suboptimal outcomes.

\section{The High Cost of Acquiring Knowledge}

There is yet another way in which having additional knowledge can have bad consequences. Even where the knowledge itself is a good thing, the cost of acquiring the knowledge can sometimes exceed the benefits of having the knowledge (cf. Rescher 1989, pp. 9-10). ${ }^{34}$ For example, certain scientific experiments are too expensive (or even unethical) to perform even though they would allow us to acquire more knowledge. In the context of the digital divide, it might be that money spent improving access to information technology could be better spent on other things, such as food or housing.

In fact, it seems quite likely that we could reach a point of diminishing returns when it comes to improving access to information technology. ${ }^{35}$ The marginal value of an additional unit of almost any good decreases (cf. Kingma 2001, pp. 30-31). For example, the more barrels of oil that you own, the less an additional barrel is worth to you. The same undoubtedly applies to knowledge. ${ }^{36}$ As a result, there will probably be a point where using any more of our limited resources to facilitate knowledge acquisition will make us worse off overall. Thus, it might be that the distribution with the best overall consequences is such that someone could have had more knowledge (without anybody else having less). In other words, it might be that the distribution with the best overall consequences is not epistemically permissible. 
However, this does not mean that we should ignore the recommendations of epistemic value theory as Goldman suggests. This only means that we need to slightly modify our definitions of "epistemically permissible" and "epistemically required." In particular, we should say that a distribution of knowledge D is epistemically permissible if no other distribution that we can actually bring about using the very same resources is epistemically better than $\mathrm{D} .{ }^{37}$ In other words, epistemically permissibility should be relativized to the amount of resources that will be used to bring about a new distribution of knowledge. In that case, even if knowledge has declining marginal utility, we should still follow the recommendations of epistemic value theory and aim for a distribution of knowledge that is epistemically permissible.

Of course, if epistemically permissibility is relativized in this way, then we cannot use epistemic value theory to identify a distribution to aim for until we know how much of our resources should be allocated toward facilitating the acquisition of knowledge. In other words, we need to know how the benefits of knowledge compare with the benefits of other goods that we might pursue. But, unsurprisingly, this is not a question that epistemology can answer by itself.

\section{THE VALUE OF EPISTEMIC VALUE THEORY}

Even if the distribution with the best overall consequences is among the epistemically permissible distributions, we still have to identify this distribution. In order to do this, we have to do an all-things-considered evaluation of the epistemically permissible distributions. But since we are going to have to do all-things-considered evaluations 
anyway, someone might object that epistemic value theory is not doing any work. It might seem simpler to just follow Goldman's suggestion and do an all-things-considered evaluation of all the distributions of knowledge that we might bring about.

There is a practical advantage, however, to focusing on epistemically permissible distributions of knowledge. By doing so, we speed up our search for a specific distribution of knowledge to aim for. We only have to do an all-things-considered evaluation of the epistemically permissible distributions (i.e., the distributions that we have determined to have good epistemic consequences).

Also, from the perspective of the epistemologist at least, there is a beneficial side effect to following the recommendations of epistemic value theory. By focusing on epistemically permissible distributions, we retain the normative role that has always been central to work in epistemology. If we followed Goldman's suggestion, the normativity of epistemology would be completely captured by the normativity of means-ends rationality. We could criticize people for choosing bad means to their epistemic ends. But we could not criticize people for choosing bad epistemic ends (such as ignorance or error). ${ }^{38}$

\section{CONCLUSION}

In order to evaluate policies for dealing with the digital divide, we need to identify the distribution of knowledge that has the best consequences. Since the principal value of access to information technology is that it leads to knowledge, work in epistemology can 
arguably help us to identify this distribution. Unfortunately, epistemic value theory cannot provide all of the answers that we will need. In particular, there may not be a single distribution of knowledge that is epistemically required. As a result, we will still have to determine which of the epistemically permissible distributions of knowledge to aim for.

Even so, there is further work to be done to sharpen and supplement the answers that epistemic value theory can give. First, I have focused on just a few of the constraints on the epistemic betterness relation that are relevant to evaluating information policies. However, in order to evaluate policies for dealing with the digital divide, it would be useful to have a complete list of constraints that are relevant to whether one distribution of knowledge is epistemically better than another. ${ }^{39}$ Second, I have argued that the distribution with the best overall consequences is likely to be an epistemically permissible distribution. It would be useful to empirically confirm this. Finally, I have claimed that epistemology can only tell us, for a fixed amount of resources, which distributions of knowledge are epistemically permissible. Thus, in order to determine how much of our limited resources should be allocated toward dealing with inequalities in access to information technology, it would be useful to know how the benefits of knowledge compare with the benefits of other goods that we might pursue.

\section{References}

Broome, J. (1991). Weighing goods. Cambridge, Massachusetts: Basil Blackwell.

Brown, M. F. (2003). Who owns native culture? Cambridge: Harvard. 
Camp, L. J., \& Tsang, R. P. (2000). Universal service in a ubiquitous digital network. Ethics and Information Technology, 2(4), 211-221.

Chabrán, R. (2001). Immigrants, global digital economies, cyber segmentation, and emergent information services. S. Luévano-Molina (ed.), Immigrant politics and the public library (pp. 131-140). Westport, Connecticut: Greenwood.

Chisholm, R. (1977). Theory of knowledge. Englewood Cliffs, New Jersey: Prentice-Hall.

Compaine, B. M. (2001). Declare the war won. B. M. Compaine (ed.), The digital divide: Facing a crisis or creating a myth? (pp. 315-335). Cambridge: MIT.

De George, R. T. (2003). The ethics of information technology and business. Malden, Massachusetts: Blackwell.

Doctor, R. D. (1992). Social equity and information technologies: Moving toward information democracy. M. E. Williams (ed.), Annual review of information science and technology (Vol. 27, pp. 43-96). Medford, New Jersey: Learned Information.

Egan, M., \& Shera, J. (1952). Foundations of a theory of bibliography. Library Quarterly, 22(2), 125-137.

Ekelund, R. B. (1970). Price discrimination and product differentiation in economic theory: An early analysis. Quarterly Journal of Economics, 84(2), 268-278. 
Erdelez, S., \& Houston, R. D. (2004). The digital divide: Who really benefits from the proposed solutions for closing the gap? Journal of Information Ethics, 13(1), 1933.

Fallis, D. (2000). Veritistic social epistemology and information science. Social Epistemology, 14(4), 305-316.

Fallis, D. (2004a). Social epistemology and the digital divide. J. Weckert, \& Y. AlSaggaf (eds.), Conferences in research and practice in information technology (Vol. 37, pp. 79-84). Sydney: Australian Computer Society. http://www.crpit.com/confpapers/CRPITV37Fallis.pdf

Fallis, D. (2004b). Epistemic value theory and information ethics. Minds and Machines, 14(1), 101-117.

Fallis, D. (2006a). Social epistemology and information science. B. Cronin (ed.), Annual review of information science and technology (Vol. 40). Medford, New Jersey: Information Today.

Fallis, D. (2006b). Epistemic value theory and social epistemology. Episteme, 2(3), 177188.

Fallis, D. (2007). Collective epistemic goals. Social Epistemology, 21(3), 267-280.

Garnham, N. (1999). Amartya Sen's "capabilities" approach to the evaluation of welfare: Its application to communications. A. Calabrese, \& J. C. Burgelman (eds.), 
Communication, citizenship and social policy (pp. 113-124). Lanham, Maryland: Rowman and Littlefield.

Goldman, A. I. (1987). Foundations of social epistemics. Synthese, 73(1), 109-144.

Goldman, A. I. (1999). Knowledge in a social world. New York: Oxford.

Goldman, A. I. (2002). Reply to commentators. Philosophy and Phenomenological Research, 64(1), 215-227.

Hacker, K. L., \& Mason, S. M. (2003). Ethical gaps in studies of the digital divide. Ethics and Information Technology, 5(2), 99-115.

Hamburg, M., Ramist, L. E., \& Bommer, M. R. W. (1972). Library objectives and performance measures and their use in decision making. Library Quarterly, 42(1), 107-128.

Harman, G. (1986). Change in view. Cambridge: MIT.

Hongladarom, S. (2002). Hope in the information society. http://pioneer.netserv.chula.ac.th/ hsoraj/web/Hope.pdf

Hull, B. (2003). ICT and social exclusion: The role of libraries. Telematics and Informatics, 20(2), 131-142.

James, F. (2001 Feb 7). FCC's Powell makes clear contrast with predecessor. Chicago Tribune. 
Johnson, D. G. (1991). Equal access to computing, computing expertise, and decision making about computers. R. Dejoie, G. Fowler, \& D. Paradice (eds.), Ethical issues in information systems (pp. 210-218). Boston: Boyd \& Fraser.

Kelly, T. (2003). Epistemic rationality as instrumental rationality: A critique. Philosophy and Phenomenological Research, 66(3), 612-640.

Kingma, B. R. (2001). The economics of information (2nd ed.). Englewood, Colorado: Libraries Unlimited.

Kirkwood, C. W. (1997). Strategic decision making. Belmont, California: Duxbury Press.

Kolata, G. (2001 Dec 30). Questions grow over usefulness of some routine cancer tests. New York Times.

Levi, I. (1967). Gambling with truth. Cambridge: MIT.

Lievrouw, L. A., \& Farb, S. E. (2003). Information and equity. B. Cronin (ed.), Annual review of information science and technology (Vol. 37, pp. 499-540). Medford, New Jersey: Information Today.

Lichtblau, E. (2001 Nov 18). Rising fears that what we do know can hurt us. Los Angeles Times.

Maher, P. (1993). Betting on theories. New York: Cambridge.

Moss, J. (2002). 'Power and the digital divide'. Ethics and Information Technology, 4(2), 159-165. 
Mueller, M. L. (2001). Universal service policies as wealth redistribution. B. M. Compaine (ed.), The digital divide: Facing a crisis or creating a myth? (pp. 179187). Cambridge: MIT.

Nozick, R. (1993). The nature of rationality. Princeton: Princeton.

Papineau, D. (2000). The evolution of knowledge. P. Carruthers, \& A. Chamberlain (eds.), Evolution and the human mind (pp. 170-206). Cambridge: Cambridge.

Quine, W. V. O. (1969). Epistemology naturalized. Ontological relativity and other essays (pp. 69-90). New York: Columbia.

Rawls, J. (1971). A theory of justice. Cambridge: Harvard.

Rescher, N. (1989). Cognitive economy. Pittsburgh: University of Pittsburgh.

Rogers, N. (1992). Dirt and disease. New Brunswick, New Jersey: Rutgers.

Rooksby, E. (2005). Information technology and social justice. Idea Group, Inc.

Sartwell, C. (1992). Why knowledge is merely true belief. Journal of Philosophy, 89(4), 167-180.

Shapiro, C., \& Varian, H. R. (1999). Information rules. Boston: Harvard Business School.

Solnick, S. J., \& Hemenway, D. (1998). Is more always better?: A survey on positional concerns. Journal of Economic Behavior and Organization, 37(3), 373-383. 
Tichenor, P. J., Donohue, G. A., \& Olien, C. N. (1970). Mass media flow and differential growth in knowledge. Public Opinion Quarterly, 34(2), 159-170.

United Nations. (1948). Universal declaration of human rights. http://www.un.org/Overview/rights.html

van den Hoven, M. J. (1995). Equal access and social justice: Information as a primary good. ETHICOMP95: An international conference on the ethical issues of using information technology (pp. 1-17). Leicester: De Montfort University.

Warschauer, M. (2002). Reconceptualizing the digital divide. First Monday, 7(7), http://www.firstmonday.org/issues/issue7_7/warschauer/

\footnotetext{
${ }^{1}$ There is certainly a sense in which printed materials, and even clay tablets, count as information technology. In this paper, however, information technology will refer exclusively to digital or electronic devices.

${ }^{2}$ As Harker and Mason (2003, p. 102) point out, there are actually many different digital divides (e.g., between ethnicities, between genders, between urban communities and rural communities, between rich and poor nations). In this paper, however, I will focus on the digital divide that cuts along socioeconomic lines within a single society.

${ }^{3}$ See Fallis (2004a, pp. 79-80) for a more detailed discussion of these arguments.

${ }^{4}$ Johnson (1991), Doctor (1992), van den Hoven (1995), and Rooksby (2005) are a few authors that do address this issue.
} 
${ }^{5}$ This paper will be concerned with which policies have the best consequences. Of course, there may also be non-consequentialist reasons for adopting particular policies. However, many (if not all) such reasons can be incorporated into a consequentialist framework with a sufficiently broad notion of consequence (cf. Broome 1991, pp. 3-4). ${ }^{6}$ In other words, epistemic value theory can help us to decide on a collective epistemic goal (cf. Fallis 2007).

${ }^{7}$ At a press conference, he once quipped that 'there's a Mercedes divide. I'd like to have one; I can't afford one" (quoted in James 2001).

${ }^{8}$ In a similar vein, it has frequently been suggested that knowledge acquisition is the main consideration when evaluating library policies (cf. Egan and Shera 1952, p. 132, Hamburg et al. 1972, p. 111).

${ }^{9}$ Access to information technology is not intrinsically valuable (cf. Chabrán 2001, p. 138, Hacker and Mason 2003, pp. 103-104). It is only valuable if it is a means to other things that we care about. For example, unless content that is relevant to one's interests is available and one has certain online skills (e.g., the ability to find, read, and evaluate such content), there is little benefit to having access to the Internet.

${ }^{10}$ Knowledge can also be intrinsically valuable (cf. Goldman 1999, p. 75). However, in the context of the digital divide, we are primarily concerned with its instrumental value. ${ }^{11}$ In his work on distributive justice, John Rawls (1971, p. 92) adopts this same sort of strategy when evaluating social policies in general. He focuses on primary goods rather than on the diverse benefits of having such goods (cf. Kirkwood 1997, pp. 24-25). Primary goods, such as liberty and income, are "things that every rational man [sic] is 
presumed to want. These goods normally have a use whatever a person's rational plan of life" (Rawls 1971, p. 62).

${ }^{12}$ It might be suggested that we ought to be concerned with the distribution of the capability of acquiring knowledge rather than with the distribution of knowledge itself (cf. Garnham 1999). The intuition here is that people should be allowed to choose for themselves how they make use of their capabilities. (In addition, we cannot actually distribute knowledge itself; we can only distribute the means to acquiring knowledge.) However, the capacity to acquire knowledge is only valuable because knowledge itself is valuable (cf. Goldman 1999, p. 351). As a result, in this paper, I will focus on the distribution of knowledge. In any event, what I have to say about distributing knowledge should also apply to distributing the capacity to acquire knowledge.

${ }^{13}$ In his work on social epistemology, Goldman (1999, p. 24) defines knowledge as true belief (cf. Sartwell 1992). Thus, he actually refers to his epistemic value theory as a theory of "veritistic value." However, nothing in this paper will turn on the precise definition of knowledge that we adopt.

${ }^{14}$ Value theory in general places certain minimal constraints (e.g., transitivity) on any betterness relation (cf. Broome 1991). Epistemic value theory simply adds additional constraints.

${ }^{15}$ This is a ceteris paribus constraint. For example, when there is a conflict, it does not say whether it is better for person $X$ to have more knowledge or for person $Y$ to have more knowledge. 
${ }^{16}$ This distribution is only "utilitarian" in the sense that it maximizes the average amount of some particular good. In this case, the good in question is knowledge rather than happiness.

${ }^{17}$ Even if there are additional constraints on the epistemic betterness relation, the "utilitarian" distribution does not seem to be epistemically required. A similar critique can be made with respect to other parts of his epistemic value theory. For example, Goldman (1999, p. 89) claims that the epistemic benefit of a true belief has the same magnitude as the epistemic cost of a false belief. However, while this may be an epistemically permissible value assignment, it does not seem to be epistemically required (cf. Fallis 2006b).

${ }^{18}$ This is analogous to a standard criticism of utilitarianism in general (cf. Rawls 1971, p. 26).

${ }^{19}$ The same sort of scenario arises with access to information technology (cf. Shapiro and Varian 1999, pp. 56-57).

${ }^{20}$ Although Rawls himself does not explicitly discuss knowledge, it clearly counts as a primary good (cf. Nozick 1993, p. 68, van den Hoven 1995).

${ }^{21}$ The justification for this theory of distributive justice is that it is what people would adopt in a fair deliberation (see Rawls 1971, pp. 17-22). In other words, it is what people would agree to if they did not already know what their position in society would be. Appealing to such a hypothetical agreement is especially appropriate in the context of the digital divide. Houston and Erdelez (2002) provide evidence that what people think should be done about the digital divide depends a lot on their position in society. 
${ }^{22}$ Article 19 of the "Universal Declaration of Human Rights" states that "everyone has the right $\ldots$ to seek, receive and impart information and ideas through any media and regardless of frontiers." Also, aiming for the Rawlsian distribution supports the adoption of universal service policies (cf. Camp and Tsang 2000).

${ }^{23}$ Don Fallis (2006b) argues that we often need to appeal to non-epistemic considerations to determine which distribution of knowledge we should aim for.

${ }^{24}$ It will require empirical study to conclusively establish that the good consequences (which include the diverse benefits of having knowledge as well as the intrinsic value of knowledge) will outweigh the bad consequences.

${ }^{25}$ For example, it is doubtful that information have-nots are more likely to be terrorists.

${ }^{26}$ Also, we are probably all better off not knowing the time and manner of our own deaths.

${ }^{27}$ This is in contrast to the more standard worry about indigenous knowledge getting into the hands of outsiders (cf. Brown 2003, pp. 11-42). In response to this example, it might be objected that the tribe was simply wrong about the dissemination of this knowledge having bad consequences. In particular, we might think that things will typically be better if the uninitiated are not kept in the dark. But I will not press this objection. ${ }^{28}$ There are many diverse benefits of having knowledge. As suggested above, knowledge is what Rawls would refer to as a primary good.

${ }^{29}$ This can happen even if the knower only has epistemic interests. For example, if a scientist knows which subjects are in the experimental group and which subjects are in the control group, it can potentially bias the results of the experiment. Also, more knowledge can sometimes lead people to acquire fewer true beliefs. For example, if I did 
know the time and manner of my own death, I might lack the motivation to go out and learn new things.

${ }^{30}$ Under the "Rawlsian" distribution of knowledge, any inequalities in knowledge possession must be to the advantage of the information have-nots, but such inequalities might still end up being very large. In other words, the "Rawlsian" distribution is consistent with a very wide digital divide.

${ }^{31}$ Such large inequalities might also have bad consequences if the information have-nots were to violently overthrow their oppressors.

${ }^{32}$ In this case, the bad consequences flow from the distribution of the knowledge rather than from the content of the knowledge.

${ }^{33}$ In a similar vein, utilitarians often argue that, as a matter of fact, overall happiness tends to be greater when happiness is more equally distributed (cf. Broome 1991, pp. 175-177).

${ }^{34}$ Even if there were no financial costs associated with acquiring the knowledge, there would typically be opportunity costs, such as time spent in the classroom (cf. Kingma 2001, p. 127).

${ }^{35}$ In 1997, a small town in Ireland received a huge grant to become an "Information Age Town." Three other towns received much smaller grants to upgrade their information technology infrastructure. Mark Warschauer (2002) reports that it is not clear that the winner ended up much better off than the runners-up. In other words, information technology seems to have a declining marginal utility.

${ }^{36}$ In fact, beyond a certain point, additional knowledge may even be counterproductive (cf. Harman 1986, p. 12). 
${ }^{37}$ In a similar vein, in discussions of the value of evidence in science, authors (e.g., Maher 1993, p. 173) typically make the assumption that gathering evidence has a fixed (usually, zero) cost. In addition, the necessity of this sort of amendment is not unique to epistemic value theory. It is going to be necessary for any specialized theory of value (e.g., nutritionally better, aesthetically better, hygienically better, etc.).

${ }^{38}$ Thomas Kelly (2003) has recently argued that epistemic rationality cannot be reduced to means-ends rationality. But there are a few philosophers (e.g., Quine 1969) who have suggested that epistemology should be such a purely descriptive enterprise.

${ }^{39}$ The exercise of using epistemic value theory to evaluate information policies can help us to compile such a list. 